\title{
The impact of cognitive functioning on mortality and the development of functional disability in older adults with diabetes: the second longitudinal study on aging
} Lisa C McGuire*, Earl S Ford and Umed A Ajani

Address: Division of Adult and Community Health, Centers for Disease Control and Prevention, 4770 Buford Highway, NE., MS K-66, Atlanta, GA 30328, USA

Email: Lisa C McGuire* - Imcguire@cdc.gov; Earl S Ford - eford@cdc.gov; Umed A Ajani - uajani@cdc.gov

* Corresponding author

Published: 0 I May 2006

BMC Geriatrics 2006, 6:8 doi:10.1/86/147|-2318-6-8
Received: 06 February 2006

Accepted: 0I May 2006

This article is available from: http://www.biomedcentral.com//47|-23/8/6/8

(c) 2006 McGuire et al; licensee BioMed Central Ltd.

This is an Open Access article distributed under the terms of the Creative Commons Attribution License (http://creativecommons.org/licenses/by/2.0), which permits unrestricted use, distribution, and reproduction in any medium, provided the original work is properly cited.

\begin{abstract}
Background: For older adults without diabetes, cognitive functioning has been implicated as a predictor of death and functional disability for older adults and those with mild to severe cognitive impairment. However, little is known about the relationship between cognition functioning on mortality and the development of functional disability in late life for persons with diabetes. We examined the relative contribution of cognitive functioning to mortality and functional disability over a 2-year period in a sample of nationally representative older US adults with diabetes who were free from cognitive impairment through secondary data analyses of the Second Longitudinal Study of Aging (LSOA II).
\end{abstract}

Methods: Participants included 559 US adults ( 232 males and 327 females) $\geq 70$ years old who had diabetes and who were free from cognitive impairment were examined using an adapted Telephone Interview of Cognitive Status (TICS), Activities of Daily Living (ADL), and Instrumental Activities of Daily Living (IADL).

Results: Multivariate logistic regression was conducted to investigate the independent contribution of cognitive functioning to three mutually exclusive outcomes of death and two measures of functional disability status. The covariates included in the model were participants' sex, age, race, marital status, educational level, duration of diabetes, cardiovascular disease (CVD) status, and self-rated health. Persons with diabetes who had the lowest levels of cognitive functioning relative to the highest level of cognitive functioning had a greater odds of dying (AOR $=0.80,95 \% \mathrm{Cl}=0.67-0.96)$ or becoming disabled $(\mathrm{AOR}=0.87,95 \% \mathrm{Cl}=0.78-0.97)$ compared to those people who were disability free.

Conclusion: Older adults with diabetes and low normal levels of cognition, yet within normal ranges, were approximately $20 \%$ more likely to die and $13 \%$ more likely to become disabled than those with higher levels of cognitive functioning over a 2-year period. Brief screening measures of cognitive functioning could be used to identify older adults with diabetes who are at increased risk for mortality and functional disability, as well as those who may benefit from interventions to prevent or minimize further disablement and declines in cognitive functioning. 


\section{Background}

Cognitive dysfunction appears to be an additional complication of diabetes [1]. Accelerated declines in cognitive functioning have been consistently reported for older and middle-aged adults with diabetes [1-9]. In a recent systematic analysis, Cukierman and colleagues concluded that people with diabetes had a 1.2 to 1.5 -fold greater change over time in measures of cognitive functioning and that the odds of future dementia was increased 1.6-fold[1]. In addition, the risk of cognitive decline was greater for those who had diabetes longer [4,5] and for those not treating their diabetes [4].

Older adults with diabetes have a heavy burden of disability and functional disability [8,10-14]. About 20-50\% of people with diabetes report having a disability, which is 2-3 times more likely than the general population [13]. One-third of people with diabetes have difficulties with at least one activity of daily living (ADL, includes bathing, dressing, etc). In addition, diabetes is shown to be related to IADL limitations [15] as 57\% have at least one limitation in instrumental activities of daily living (IADL, includes shopping, preparing meals, etc) [12].

Cognitive impairment and functional disability have similar trajectories associated age and are important public health issues of an aging population [15]. For older adults without diabetes, cognitive functioning has been implicated as a predictor of functional disability for older adults [3,15-21] and those with mild to severe cognitive impairment $[22,23]$. Diabetes is a common chronic condition in older adults that afflicts a large proportion of the aging population as approximately 10.3 million or $20.9 \%$ of adults aged $\geq 60$ years old had diabetes in 2005 [24] and the diabetes prevalence rates for older adults have been increasing steadily since the 1980s [25]. However, little is known about the relationship between cognition functioning and the development of functional disability and mortality in late life for persons with diabetes. We examined the relative contribution of cognitive functioning to mortality and functional disability over a 2-year period in a sample of nationally representative older US adults with diabetes who were free from cognitive impairment through secondary data analyses of the Second Longitudinal Study of Aging (LSOA II) [26].

\section{Methods}

\section{Participants}

Data for the present investigation came from the LSOA II, a publicly available data set, which consists of a nationally representative sample with a multistage complex sampling design. The baseline of LSOA II was the 1994 National Health Interview Survey, Second Supplement on Aging II (SOA II), conducted by the Centers for Disease Control and Prevention after ethical approval for the study was obtained by the National Center for Health Statistics' Research Ethics Review Board. Participation in the survey was voluntary and confidentiality of respondents and their responses was assured by adherence to Section 308(d) of the Public Health Service Act (42 USC 242 m). In addition to receiving an advance letter describing the study prior to the interview, the interviewer described the voluntary nature of the study, participants' right to withdrawal at anytime, and the confidentiality measures employed. Informed consent then was obtained verbally from the participant when they gave their permission to proceed with the interview.

The SOA II was comprised of 9,447 community-dwelling, civilian men and women who were at least 70 years old (mean $=77.3, \mathrm{SE}=.20$ ). The follow-ups were conducted primarily using a Computer-Assisted Telephone Interview system. The data in the first follow-up, were collected between May 1997 and May 1998, while the second follow-up was obtained between June 1999 and August 2000. Cognitive measures were collected for the first time during the first follow-up; therefore, we limited our analyses to 559 individuals with diabetes who completed cognitive measures without proxy.

\section{Materials}

Cognitive functioning was assessed at both follow-ups using an adapted telephone interview for cognitive status (TICS) [27]. Cognitive functioning assessed two independent factors of cognition: mental status (orientation, registration, and attention) and memory (immediate verbal memory). Participants' scores on the mental status items (0-10 points; e.g., Who is the president and vicepresident?; What is used to cut paper?; What is a desert plant?; What is the day/date/month/year?; counting backwards from 20 and from 86) and memory task (0-10 points; 10 item list of concrete nouns) were summed resulting in a cognitive functioning score ranging from 0 to 20 , with higher scores indicating higher levels of cognitive functioning. Methodologically, assessing cognitive functioning via the telephone is a reliable and valid approach [28-31]. Participants whose cognitive score was at least 1.5 standard deviation units below the mean performance were considered to have mild to severe cognitive impairment and were excluded from the analyses [32,33].

Diabetes was assessed by self-report, which is considered a reliable and valid indicator diabetes status $[10,12,15,34-$ 36]. Participants indicated whether they had diabetes at baseline and if they now have diabetes at first and second follow-ups. We considered people to have diabetes if they indicated "yes" to the diabetes questions. 
Functional disability status was measured using selfreported ADLs and IADLs during the first and second follow-ups. ADLs, which are comprised of basic self-care tasks necessary for an adult to live independently, include bathing, dressing, eating, transferring, walking, and toileting, were assessed in the LSOA II. IADLs are higherordered skills that are also necessary for independent living. The IADL tasks assessed on the LSOA II were preparing meals, grocery shopping, managing money, using the telephone, doing light/heavy housework, and managing medications. Participants were classified into one of three mutually exclusive categories, death and two categories of functional disability status by their self-reported ability in the second follow-up to perform ADL and IADL tasks: 1). deceased - died between first and second follow-up as indicated by interviews with surviving family and friends; 2). ADL and/or IADL disabled - unable to perform at least one ADL task and/or at least one IADL task; and 3). disability free - able to perform all ADL and IADL activities. In addition, we controlled for participants functional disability status at the first follow-up.

Covariates modeled as predictors of mortality and functional disability status included measures of participants' sex, age, race, marital status, educational level, duration of diabetes, CVD, and self-rated health. Age, education, and duration of diabetes were continuous variables. The duration of diabetes was calculated based on self-reported year of diagnosis and year of first follow-up. Race was classified into two categories (white and nonwhite). Marital status was recoded into married or not married, with the not married classification including individuals who were widowed, never married, and separated/divorced. Cardiovascular disease (CVD) status was comprised of people who indicated that they had hypertension or that they had experienced a heart attack or a stroke. Self-rated health was recoded in two classifications (excellent or very good, good to poor).

\section{Statistical analyses}

To account for the complex sampling design, SUDAAN statistical software, version 9.0 [37] was used in all statistical analyses [38]. Multivariate logistic regression models [39] were fit using the MULTILOG procedure with the GENLOGIT (generalized logit) option of SUDAAN after verifying the assumption of multicollinearity [40]. The multivariate logistic regression model was fit using the MULTILOG procedure of SUDAAN. Adjusted odds ratios (AOR) for each of the three levels of outcomes, mortality and functional disability status, and cognitive functioning relative to the disability free were provided along with their corresponding 95\% confidence intervals.

\section{Results}

Of the 9447 participants of the SOA II, 1183 died and 426 were missing in the $1^{\text {st }}$ follow-up, resulting in 7838 first follow-up participants. This sample of 7838 participants consisted of 1178 people with diabetes that was further reduced to 650 people with diabetes who completed the cognitive tasks at first follow-up without mild to severe cognitive impairment $(n=56)$; an additional 91 participants were excluded due to incomplete information for covariates, diabetes status, and outcome variables. There was no difference in age $(p=0.122)$, educational attainment $(p=0.799)$, and length of time with diabetes $(p=$ 0.290 ) between those who were excluded due to incomplete information and those who were included in the sample. However, those who were excluded due to incomplete information compared to those who were included in the sample had lower first follow-up cognitive functioning $(p=0.003)$.

The analysis consisted of 559 older adults (232 males and 327 females) with diabetes and no evidence of mild to severe cognitive functioning. A first follow-up, they were on average $77.81(\mathrm{SE}=.17)$ years old and on average were diagnosed with diabetes $14.43(\mathrm{SE}=.43)$ years prior. The sample consisted of community-dwelling people who were primarily Caucasian ( $n=477$, weighted percentage $88.79 \%, S E=1.39)$. More than half were female $(n=327$, weighted percentage $58.00 \%, S E=2.13)$, who were unmarried ( $n=321$, weighted percentage $56.28 \%$, $S E=$ $2.17)$, with more than 2 chronic condition $(n=307$, weighted percentage $57.92 \%, S E=2.02)$, with CVD $(n=$ 399 , weighted percentage $71.40 \%, S E=2.14)$, who were disability free at first follow-up ( $n=266$, weighted percentage $48.64 \%, S E=2.18)$ and rated their health as excellent or very good ( $n=160$, weighted percentage $28.14 \%$, $S E=2.03)$ or as fair or poor $(n=399$, weighted percentage $71.86 \%, S E=2.03)$.

People with diabetes who rated their health as at least very good at first follow-up were more likely to be disability free than those people who rated their health as good or fair or poor (Table 1). People with diabetes who had more than 2 chronic health conditions were more likely to have died and to have become disabled, while those with fewer chronic conditions were disability free. Those with diabetes and CVD were more likely to have died or to have become disabled than those without CVD. People with diabetes without a functional disability tended to have higher levels of educational attainment and cognitive functioning than people who are dead or disabled. People with diabetes without a functional disability tended to have higher levels of educational attainment and cognitive functioning than people who died or became disabled. There was no relationship between death and functional disability status and duration of diabetes. 
A series of multivariate logistic regression models predicting the combined 2-year mortality and functional disability status were calculated after controlling for the covariates of participants' sex, age, race, marital status, educational level, duration of diabetes, CVD, and selfrated health. The multivariate logistic regression models allowed for multiple outcomes of mortality and functional disability to be compared simultaneously to the reference group of disability free. Persons with diabetes who had the lowest levels of cognitive functioning relative to the highest level of cognitive functioning had greater odds of dying ( $\mathrm{AOR}=0.80,95 \% \mathrm{CI}=0.67-0.96)$ or becoming disabled $(\mathrm{AOR}=0.87,95 \% \mathrm{CI}=0.78-0.97)$. Furthermore, for death and functional disability, a graded relationship with cognitive functioning was apparent.

\section{Discussion}

In this longitudinal study of US adults with diabetes aged $\geq 70$ years who were functioning cognitively in the normal range, poor cognitive functioning was a significant and independent predictor of subsequent mortality and the development of functional disability. Persons with diabetes and lower levels of cognitive functioning were more likely to die or to become functionally disabled than those with the higher levels of cognition. Interestingly, length of diabetes was not related to mortality or functional disability.

Consistent with previous research, which does not focus on older adults with diabetes, we found that cognitive functioning is a predictor of functional disability $[3,15-$ 21]. Older adults with diabetes and low normal levels of cognition were approximately $20 \%$ more likely to die and $13 \%$ more likely to become disabled than those with higher levels of cognitive functioning over a 2-year period. This finding is alarming since accelerated declines in cognitive functioning have been consistently reported for older and middle-aged adults with diabetes [1-9].

The accelerated cognitive aging associated with diabetes suggests a more rapid aging of the central nervous system compared to older adults without diabetes [27]. The performance of people with diabetes on the TICS is equivalent to aging 4 years [6]. There are several plausible biological explanations of the relationship between diabetes and accelerated cognitive aging. Diabetes may interact with normative aging processes by additionally decreasing hippocampal volume resulting in cognitive decrements beginning in the 60s, manifesting in mainly memory-related changes [5]. Cerebro- and cardiovascular disease also might explain the association between diabetes and cognitive impairment because diabetes is a risk factor for stroke and hypertension both of which are predictors of dementia [6]. Abnormal levels of blood glucose at a cellular level could result in cerebro- and cardiovascu- lar disease from failures to manage and monitor their diabetes properly [6].

Cognitive functioning has been identified as an important factor related to adherence by older adults to antihypertensive and arthritis treatment regimens [41] as well as remembering medical information [42]. Declining cognitive functioning in people with diabetes can have implications for adherence to treatment and to medication regimens, [9] the latter an IADL task. Sinclair and colleagues [2] reported that people who had diabetes and lower levels of cognitive functioning were less likely to be involved in monitoring their diabetes and in their treatment regimen, resulting in more hospitalizations, more ADL limitations, and the need for more personal assistance; thus, increased functional disability and mortality.

The relationship between cognitive functioning and adherence to treatment appears bidirectional. To minimize diabetes-related declines in cognitive functioning, older adults with diabetes should monitor their diabetes and adhere to treatment regimens [43]. It has been suggested that, in comparison with people with diabetes who do not adhere to their treatment regimen, cognitive decline is less in people adhering to either a monotherapy (use of sulfonylurea, metformin, or thiazolidinedione) or combination (sulfonylurea with another glucose-lowering agent, insulin, or metformin and insulin) $[2,43]$, but other research does not support this finding with people who are using short-term glycemic control.[20]

Changes in performance on tasks of cognitive functioning may quickly and efficiently demonstrate changes in neuropsychological functioning and serve as a warning symptom for hypoglycemia [6]. That also can be an early indicator of future functional disability. The importance of cognition on functional disability was noted by observing the abilities of older adults that allow them to live independently, such as cognitive functioning, might be more important in predicting functional disability, institutionalization, and subsequently death than their medical diagnoses [2]. This is especially of concern for older adults with diabetes, considering the reported accelerated rates of cognitive decline in this group versus those without diabetes $[1,44]$.

Our study demonstrates the potential of basic cognitive screening measures, which could have implications for health-care providers. Several brief measures to assess cognitive functioning are available that have respectable psychometric properties, such as the TICS, [27] Mini-Mental State Exam, Modified Mini-Mental State Exam, and the Short Portable Mental Status Questionnaire [45]. These instruments could allow patients who might be at the greatest risk of cognitive impairment, and subsequent 
Table I: Weighted Percentages or Means (Standard Error) of Mortality and Functional Disability Status among US Adults with Diabetes Mellitus aged $\geq 70$, Longitudinal Study of Aging II, 1997/1998-1999/2000.

\begin{tabular}{|c|c|c|c|c|c|}
\hline \multirow[b]{2}{*}{ Characteristics } & \multirow[b]{2}{*}{$n$} & \multicolumn{4}{|c|}{ Functional disability status at second follow-up* } \\
\hline & & Dead $(n=67)$ & Disabled $(n=321)$ & Non-Disabled $(n=|7|)$ & $p$-value \\
\hline Sex, \% & & & & & 0.06 \\
\hline Male & 232 & $15.16(2.30)$ & $51.20(3.15)$ & $33.65(3.17)$ & \\
\hline Female & 327 & $11.24(1.84)$ & $60.60(2.48)$ & $28.15(2.18)$ & \\
\hline Mean age at study entry, yrs & 559 & $77.92(0.51)^{\mathrm{a}}$ & $78.18(0.28)^{b}$ & $76.69(0.27)^{\mathrm{a}, \mathrm{b}}$ & $<0.01$ \\
\hline Race or Ethnicity, \% & & & & & 0.40 \\
\hline White & 477 & $12.79(1.45)$ & $55.90(2.16)$ & $31.31(2.07)$ & \\
\hline Other & 82 & $13.67(5.03)$ & $62.60(6.89)$ & $23.73(5.02)$ & \\
\hline Marital status, \% & & & & & 0.18 \\
\hline Married & 238 & $13.64(2.26)$ & $52.04(3.49)$ & $34.32(3.15)$ & \\
\hline Unmarried & 321 & $12.30(1.92)$ & $60.24(2.54)$ & $27.46(2.4 I)$ & \\
\hline Mean cognitive functioning & 559 & $13.00(0.30)^{c}$ & $13.4 \mid(0.12)^{d}$ & $14.42(0.18)^{c, d}$ & $<0.01$ \\
\hline Mean educational attainment, yrs & 559 & $10.75(0.37)^{e}$ & $10.09(0.20)^{f}$ & $12.19(0.22)$ e.f & $<0.01$ \\
\hline Mean duration of diabetes, yrs & 559 & $13.48(0.97)$ & $14.50(0.62)$ & $13.77(0.85)$ & 0.62 \\
\hline \# Chronic conditions, \% & & & & & $<0.01$ \\
\hline $0-2$ & 252 & $9.00(1.92)$ & $48.94(3.47)$ & $42.06(3.52)$ & \\
\hline$>2$ & 307 & $16.08(2.18)$ & $62.99(2.58)$ & $20.94(2.26)$ & \\
\hline CVD, \% & & & & & $<0.01$ \\
\hline Yes & 399 & $14.22(1.74)$ & $61.22(2.43)$ & $24.57(2.10)$ & \\
\hline No & 160 & $9.57(1.74)$ & $45.25(4.13)$ & $45.17(4.21)$ & \\
\hline Prior Disability Status, \% & & & & & $<0.01$ \\
\hline Disabled & 293 & $14.98(2.20)$ & $72.56(2.62)$ & $12.45(1.88)$ & \\
\hline Non-Disabled & 266 & $10.68(1.93)$ & $39.86(3.19)$ & $49.47(3.21)$ & \\
\hline Self-rated health, \% & & & & & $<0.01$ \\
\hline Excellent/very good & 160 & $7.06(2.06)$ & $42.57(3.69)$ & $50.37(3.87)$ & \\
\hline Good/fair/poor & 399 & $15.17(1.84)$ & $62.17(2.32)$ & $22.67(2.09)$ & \\
\hline TOTAL & 559 & $12.89(1.40)$ & $56.65(1.98)$ & $30.46(1.84)$ & \\
\hline
\end{tabular}

Abbreviations: ADL, activities of daily living; IADL instrumental activities of daily living; NA not applicable. Items with like subscripts are statistically significant from each other $(p<0.05)$.

$*$ Weighted estimates.

death or functional disability to be identified and targeted for interventions.

Practitioners should keep in mind that depression has been shown to impair cognitive functioning, which is important because the rates of depression are higher in people with diabetes [8]. Bruce and colleagues [46] reported that in their sample of people with diabetes who were 70 years old and older, $14.2 \%$ were clinically depressed, $50.2 \%$ reported one or more depressive symptoms, and only $36 \%$ were free of depressive symptoms.
Various cognitive interventions have been successful at reversing age-related decrements in the cognitive components of inductive reasoning and spatial ability over 7 years, [42] improving the IADL task of managing medications, [47] and improving short-term memory performance in patients with Alzheimer's disease [48]. A challenge for planners and policy makers is to understand the heterogeneity of the trajectory of functional disability, as some persons steadily decline, resulting in their institutionalization or death, while others experience fluctuations and reversals of functional disability $[12,36]$. Understanding 
predictors of functional disability and how interventions relate to its incidence might provide some insight.

Our study has several limitations. First, as in other studies [19], functional disability outcomes were assessed using respondent-reported ADL and IADL measures instead of performance-based tasks. Although, performance-based measures might be a desired method of assessment, they may not reflect adaptations a person makes to successfully complete a task, but respondent-reported ADL measures can reduce the amount of missing data. Second, unfortunately, medication adherence and depression were not assessed on the LSOA II, which can potentially impair cognition. Despite these limitations, our prospective study contributes to the literature by emphasizing the importance of cognitive functioning in the development of functional disability and mortality in a representative population of older adults with diabetes who were free of cognitive impairment.

\section{Conclusion}

Cognitive functioning among persons with diabetes is predictive of death and the development of functional disability over a 2-year interval. Older adults with diabetes and low normal levels of cognition, yet within normal ranges, were approximately $20 \%$ more likely to die and $13 \%$ more likely to become disabled than those with higher levels of cognitive functioning over a 2 -year period. Health-care providers should consider using brief cognitive screening measures as indicators of mortality and disablement in their older patients with diabetes. This will allow at-risk older adults with diabetes to be targeted for interventions minimizing cognitive decline and functional disability, as well as targeting interventions and educational materials focusing on adherence to treatment and diabetes monitoring to appropriate individuals. These interventions potentially could minimize accelerated cognitive aging associated with diabetes; thus, delaying mortality and the development of functional disability.

\section{Competing interests}

The author(s) declare that they have no competing interests.

\section{Authors' contributions}

All authors contributed to the conception and design of the study, statistical analyses and interpretation of the data, revising the manuscript for critical content, and approved the final manuscript.

\section{Funding source}

None

\section{Acknowledgements}

The authors would like to acknowledge the 3 Reviewers for their insightful comments that enhanced our project.

Disclaimer: The findings and conclusions in the article are those of the authors and do not necessarily represent the view of the Centers for Disease Control and Prevention.

\section{References}

I. Cukierman T, Gerstein HC, Williamson JD: Cognitive decline and dementia in diabetes - systematic overview of prospective observational studies. Diabetologia 2005, 48:2460-2469.

2. Hewer W, Mussell M, Rist F, Kulzer B, Bergis K: Short-term effects of improved glycemic control on cognitive function in patients with type 2 diabetes. Gerontology 2003, 49:86-92.

3. McGuire LC, Ford ES, Ajani UA: Cognitive Functioning as a Predictor of Functional Disability in Later Life. Am J Geriatr Psychiatry 2006, 14:36-42.

4. Logroscino G, Kang JH, Grodstein F: Prospective study of type 2 diabetes and cognitive decline in women aged 70-8I years. BMJ 2004, 328:548.

5. Kumari M, Marmot M: Diabetes and cognitive function in a middle-aged cohort: findings from the Whitehall II study. Neurology 2005, 65:1597-1603.

6. Coker LH, Shumaker SA: Type 2 diabetes mellitus and cognition: an understudied issue in women's health. J Psychosom Res 2003, 54:129-139.

7. Hassing LB, Grant MD, Hofer SM, Pedersen NL, Nilsson SE, Berg S, McClearn G, Johansson B: Type 2 diabetes mellitus contributes to cognitive decline in old age: a longitudinal populationbased study. J Int Neuropsychol Soc 2004, 10:599-607.

8. Bruce DG, Casey GP, Grange V, Clarnette RC, Almeida OP, Foster JK, Ives FJ, Davis TM: Cognitive impairment, physical disability and depressive symptoms in older diabetic patients: the Fremantle Cognition in Diabetes Study. Diabetes Res Clin Pract 2003, 61:59-67.

9. Sinclair AJ, Girling AJ, Bayer AJ: Cognitive dysfunction in older subjects with diabetes mellitus: impact on diabetes self-management and use of care services. All Wales Research into Elderly (AWARE) Study. Diabetes Res Clin Pract 2000, 50:203-2I2.

10. Gregg EW, Mangione CM, Cauley JA, Thompson TJ, Schwartz AV, Ensrud KE, et al.: Diabetes and incidence of functional disability in older women. Diabetes Care 2002, 25:6I-67.

II. Wu JH, Haan MN, Liang J, Ghosh D, Gonzalez HM, Herman WH: Diabetes as a predictor of change in functional status among older Mexican Americans: a population-based cohort study. Diabetes Care 2003, 26:314-319.

12. Furner SE, Giloth BE, Arguelles L, Miles TP, Goldberg JH: A co-twin control study of physical function in elderly African American women. J Aging Health 2004, 16:28-43.

13. Songer TJ: Disability in diabetes. In Diabetes in America Edited by: Harris MI, Cowie CC, Stern MP, Boyko EJ, Reiber GE, Bennett PH. Washington, DC: U.S. Government Printing Office; 1995:429-448.

14. Dunlop DD, Manheim LM, Sohn M-W, Liu X, Chang RW: Incidence of functional limitation in older adults: The impact of gender, race, and chronic conditions. Arch Phys Med Rehabil 2002, 83:964-971.

15. Barberger-Gateau P, Fabrigoule C: Disability and cognitive impairment in the elderly. Disabil Rehabil 1997, 19:175-193.

16. Gill TM, Williams CS, Richardson ED, Tinetti ME: Impairments in physical performance and cognitive status as predisposing factors for functional dependence among nondisabled older persons. J Gerontol A Biol Sci Med Sci 1996, 5 I:M283-M288.

17. Comijs HC, Dik MG, Aartsen MJ, Deeg DJ, Jonker C: The impact of change in cognitive functioning and cognitive decline on disability, well-being, and the use of healthcare services in older persons. Results of Longitudinal Aging Study Amsterdam. Dement Geriatr Cogn Disord 2005, 19:316-323.

18. Herzog AR, Wallace RB: Measures of cognitive functioning in the AHEAD Study. J Gerontol B Psychol Sci Soc Sci 1997, 52:37-48.

19. Kempen GI, Steverink N, Ormel J, Deeg DJ: The assessment of $A D L$ among frail elderly in an interview survey: self-report 
versus performance-based tests and determinants of discrepancies. J Gerontol B Psychol Sci Soc Sci 1996, 5 I:P254-P260.

20. Steen G, Sonn U, Hanson AB, Steen B: Cognitive function and functional ability. A cross-sectional and longitudinal study at ages 85 and 95 in a non-demented population. Aging (Milano) 2001, 13:68-77.

21. Stuck AE, Walthert JM, Nikolaus T, Büla CJ, Hohmann C, Beck JC: Risk factors for functional status decline in community-living elderly people: a systematic literature review. Soc Sci Med 1999, 48:445-469.

22. Albert SM, Tabert MH, Dienstag A, Pelton G, Devanand D: The impact of mild cognitive impairment on functional abilities in the elderly. Curr Psychiatry Rep 2002, 4:64-68.

23. Tabert MH, Albert SM, Borukhova-Milov L, Camacho Y, Pelton G, Liu $X$, et al:: Functional deficits in patients with mild cognitive impairment: prediction of AD. Neurology 2002, 58:758-764.

24. Centers for Disease Control and Prevention: National diabetes fact sheet: general information and national estimates on diabetes in the United States, 2005 Atlanta, GA: Department of Health and Human Services, Centers for Disease Control and Prevention; 2005.

25. Centers for Disease Control and Prevention: Prevalence of Diagnosed Diabetes per 100 Population, by Age, United States, 1980-2004 2005 [http://www.cdc.gov/diabetes/statistics/prev/national/tableby age.htm]. Atlanta, GA: U.S. Department of Health and Human Services, Centers for Disease Control and Prevention

26. National Center for Health Statistics: The Second Longitudinal Study of Aging, 1994-2000 Wave 3 Survivor File, Version SF 2. I. Public-use data file and documentation 2002 [http://www.cdc.gov/nchs/about/otheract/ aging/w3sf.htm].

27. Brandt J, Spencer M, Folstein M: The telephone interview for cognitive status. Neuropsychiatry Neuropsychol Behav Neurol 1998, I:III-II7.

28. Bush TL, Miller SR, Golden AL, Hale WE: Self-report and medical record report agreement of selected medical conditions in the elderly. Am J Public Health 1989, 79: I554-1556.

29. Harlow SD, Linet MS: Agreement between questionnaire data and medical records. The evidence for accuracy of recall. Am J Epidemiol 1989, 129:233-248.

30. Bergmann MM, Jacobs EJ, Hoffmann K, Boeing H: Agreement of self-reported medical history: comparison of an in-person interview with a self-administered questionnaire. Eur J Epidemiol 2004, 19:4III-4I6.

31. Simpson CF, Boyd CM, Carlson MC, Griswold ME, Guralnik JM, Fried LP: Agreement between self-report of disease diagnoses and medical record validation in disabled older women: factors that modify agreement. J Am Geriatr Soc 2004, 52:123-I 27.

32. Nasreddine ZS, Phillips NA, Bedirian V, Charbonneau S, Whitehead V, Collin I, et al:: The Montreal Cognitive Assessment, MoCA: a brief screening tool for mild cognitive impairment. J Am Geriatr Soc 2005, 53:695-699.

33. Petersen RC: Mild cognitive impairment clinical trials. Nat Rev Drug Discov 2003, 2:646-653.

34. Ford ES, Herman WH: Leisure-time physical activity patterns in the U.S. diabetic population. Findings from the 1990 National Health Interview Survey - Health Promotion and Disease Prevention Supplement. Diabetes Care 1995, 18:27-33.

35. Ford ES, Mokdad AH: Fruit and vegetable consumption and diabetes mellitus incidence among U.S. adults. Prev Med 2001 32:33-39.

36. Fultz $\mathrm{NH}$, Ofstedal MB, Herzog AR, Wallace RB: Additive and interactive effects of comorbid physical and mental conditions on functional health. J Aging Health 2003, 15:465-48I.

37. Research Triangle Institute: SUDAAN Language Manual, Release 9.0 Research Triangle Park, NC: Research Triangle Institute; 2004.

38. Brogan DJ: Pitfalls of using standard statistical software packages for sample survey data. In Encyclopedia of Biostatistics Edited by: Armitage P, Colton T. New York: Wiley; 1998:4167-4I74.

39. Korn EL, Graubard BI: Analysis of Health Surveys New York: Wiley; 1999.

40. Belsley DA, Kuh E, Welsch RE: Regression diagnostics: indentifying influential data and sources of collinearity New York: John Wiley \& Sons; 1980.

4I. Perlmuter LC, Hakami MK, Hodgson-Harrington C, Ginsberg J, Katz J, Singer DE, et al.: Decreased cognitive function in aging noninsulin-dependent diabetic patients. $A m 」$ Med 1984 , 77:1043-1048
42. Park DC, Gutchess $\mathrm{AH}$ : Cognitive aging and everyday life. In Cognitive aging: a primer Edited by: Park DC, Schwarz N. Philadelphia, PA: Taylor \& Francis Group; 2000:217-232.

43. Wu JH, Haan MN, Liang J, Ghosh D, Gonzalez HM, Herman WH Impact of antidiabetic medications on physical and cognitive functioning of older Mexican Americans with diabetes mellitus: a population-based cohort study. Ann Epidemiol 2003. 13:369-376.

44. Gispen $\mathrm{WH}$, Biessels G]: Cognition and synaptic plasticity in diabetes mellitus. Trends Neurosci 2000, 23:542-549.

45. Tun PA, Perlmuter LC, Russo P, Nathan DM: Memory self-assessment and performance in aged diabetics and non-diabetics. Exp Aging Res 1987, 13:151-157.

46. Willis SL, Nesselroade CS: Long-term effect of fluid ability training in old-old age. Dev Psychol 1990, 26:905-9/0.

47. Camp CJ, Foss JW, Stevens AB, Reichard CC, McKitrick LA, $O$ 'Hanlon AM: Memory training in normal and demented elderly populations: the E-I-E-I-O model. Exp Aging Res 1993 , 19:277-290

48. Anderson RT, James MK, Miller ME, Worley AS, Longino CF: The timing of change: patterns in transitions in functional status among elderly persons. J Gerontol B Psychol Sci Soc Sci 1998, 53:SI7-S27.

\section{Pre-publication history}

The pre-publication history for this paper can be accessed here:

http://www.biomedcentral.com/1471-2318/6/8/prepub
Publish with Bio Med Central and every scientist can read your work free of charge

"BioMed Central will be the most significant development for disseminating the results of biomedical research in our lifetime. "

Sir Paul Nurse, Cancer Research UK

Your research papers will be:

- available free of charge to the entire biomedical community

- peer reviewed and published immediately upon acceptance

- cited in PubMed and archived on PubMed Central

- yours - you keep the copyright 